\section{Molecular Identification of Cultivable Bacteria From Infected Root Canals Associated With Acute Apical Abscess}

\author{
Letícia M. M. Nóbrega ${ }^{1}$, Francisco Montagner ${ }^{1,2},{ }^{2}$ Adriana C. Ribeiro ${ }^{3}$, Márcia
}

A. P. Mayer ${ }^{3}$, Brenda P. F. A. Gomes ${ }^{1}$

\author{
'Department of Restorative \\ Dentistry, Endodontics Division, \\ Piracicaba Dental School, UNICAMP \\ - Universidade Estadual de \\ Campinas, Piracicaba, SP, Brazil \\ ${ }^{2}$ Department of Conservative \\ Dentistry, Endodontics Division, \\ UFRGS - Universidade Federal do Rio \\ Grande do Sul, Porto Alegre, RS, Brazil \\ ${ }^{3}$ Department of Oral Microbiology, \\ Institute of Biomedical Science, \\ USP - Universidade de São \\ Paulo, São Paulo, SP, Brazil
}

Correspondence: Profa. Dra. Brenda P. F. A. Gomes, Avenida Limeira 901, 13414-018 Piracicaba, SP, Brasil, Tel: +55-19-2106-5343. e-mail: bpgomes@fop.unicamp.br

Key Words: root canals, endodontics, microorganisms, abscess, sequencing.

\section{Introduction}

Acute apical abscesses (AAA) are caused by bacteria that egress the infected root canal and invade the periradicular tissues to establish an extraradicular infection and evoke purulent inflammation (1). Clinically, the disease is characterized by spontaneous pain, tenderness/pain to percussion and pain on palpation. The presence of softtissue swelling indicates diffusion through bone and may result in life-threatening conditions if immediate treatment is not provided (2).

Endodontic therapy is essentially a debridement procedure and elucidating the microbial ecology of endodontic infections is a necessary step to understand the necessity of microbial control during all phases of endodontic treatment (1-4).

The microbiota of root canal infections with pulp necrosis and acute periapical abscesses have traditionally been studied by culture technique (5-7) and recently by molecular approaches in order to get a comprehensive view of the diversity of microbial population $(2,3,8,9)$.

One of the advantages of the culture technique is that it allows the identification of a broad-range of microorganisms, the quantification of all major viable microorganisms, the antimicrobial susceptibility of the isolates, among others. Usually, microorganisms growing on culture plates exist in higher number in root canals among those that are cultivable (10).

Cultivation procedures rely on isolation, growth, and laboratory identification by morphology and biochemical tests. However even the successful cultivation of one microorganism does not necessarily mean that it will be successfully identified. Culture-dependent identification is based on phenotypic behaviors observed in reference strains, with predictable biochemical and physical properties under optimal growth conditions (11). Yet, many phenotype-related factors can lead to difficulties in identification (i.e. only at the genus level) and even to misidentification, as one species can be assigned to another based on incomplete data. Furthermore, database does not usually include newly named species or as-yetuncharacterized species $(4,10)$.

The $16 \mathrm{~S}$ rRNA gene sequencing approach has become the reference method for bacterial sequencing and taxonomy. This molecular method can provide a more precise and reliable identification of bacteria that are difficult to identify or that cannot be precisely identified by available phenotypic tests. Moreover it can be used in the identification of both cultivable and as-yet-uncultivated bacteria, without the need for cultivation (10).

Microbiological investigations of root canals of teeth 
with acute primary endodontic infection have reported that they harbor a mixed and complex microbiota, composed predominantly by anaerobic Gram-negative bacteria. Facultative and Gram-positive bacteria also play an important role in this sort of infection, acting synergistically and making even more complex the antigenicity of this infection to the host's immune system. However, there should be more species involved as many phenotype-related factors can lead to difficulties in identification and even to misidentification $(6,7,12)$.

The aim of this work was to investigate the bacterial composition found in root canals of teeth associated with AAA by molecular identification of cultivable bacteria, using the $16 \mathrm{~S}$ rRNA gene sequencing technique.

\section{Material and Methods}

\section{Patient Selection and Clinical Examination}

Twenty patients who attended a University dental emergency service because of pulp necrosis and infected root canals with AAAs, including swollen soft tissue, participated in the study. The pulp status was assessed through thermal sensitivity test, using the refrigerating spray (Endo-Ice; Maquira, Maringa, PR, Brazil).

The diagnosis of periapical abscesses was based on the presence of necrotic pulp tissues, spontaneous pain, pain on percussion, pain on palpation, associated with localized or diffuse swelling. Radiographic examination was performed to evaluate the root canal treatment status and presence of periapical pathology.

The selected teeth $(n=20)$ had received no prior endodontic treatment. Subjects who received antibiotic treatment within the preceding three months, teeth with periodontal probing depth greater than $4 \mathrm{~mm}$, and subjects with systemic diseases such as diabetes, coronary heart disease, respiratory diseases and osteoporosis were not included in the study.

The local Human Volunteers Research and Ethics Committee approved the study, and all patients signed an informed consent form.

\section{Root Canal Sampling and Culturing}

Root canal sampling and culturing methods for microbial isolation and identification were performed as described previously by Gomes et al. (13) and Montagner et al. $(2,8)$.

Dental caries and existing restorations were removed without exposure of the canals. The tooth was isolated from the oral cavity with a rubber dam. The operative field was disinfected with 30\% hydrogen peroxide, followed by $2.5 \%$ sodium hypochlorite, which was inactivated with $5 \%$ sodium thiosulphate. Samples were taken from both external tooth surface and access cavity after disinfection to guarantee the absence of contaminants. No positive growth should be observed for these two samples. If so, the respective root canal sample was immediately excluded from the study.

A two-stage, access cavity preparation was made under manual irrigation with sterile saline solution without the use of water spray, and by using a sterile high-speed diamond bur. The first stage was performed to promote removal of major contaminants. In the second stage before entering the pulp chamber, the access cavity was disinfected according to the protocol described above. The disinfection of the internal surface of the access cavity was monitored as previously described and all procedures were performed as aseptically as possible. A new sterile bur was used during irrigation with sterile saline to access the canal. In each case, even in multi-rooted teeth, a single root canal was sampled in order to confine the microbial evaluation to a single ecological environment.

The microbial samples were collected with three sterile paper points \#20 (Dentsply-Maillefer, Ballaigues, Switzerland), which were consecutively placed for 60 s into the full length of the canal (as determined radiographically). In those cases where a dry canal was identified, an additional sterile paper point moistened in sterile saline was used to ensure sample acquisition. In the case of a wet root canal, as many paper points as needed were used to absorb all the fluid inside the canal. The paper points were pooled in a sterile tube containing $1 \mathrm{~mL}$ of pre-reduced Viability Medium Göteborg Agar (VMGA III) transport medium. When tooth had a narrow root canal interfering with the penetration of the paper point, patency was accomplished through minimal instrumentation with a \#10 file ( $\mathrm{C}^{+}$Files, Dentsply). The file had its cable removed and was transferred to the tube containing $1 \mathrm{~mL}$ VMGA III transport medium. If the tooth was multi-rooted, the largest canal in the root was sampled. The samples were transported to the microbiology laboratory within $15 \mathrm{~min}$ to an anaerobic workstation (Don Whitley Scientific, Bradford, UK).

In the anaerobic chamber, the endodontic samples were serially diluted 10 times in tubes containing Fastidious Anaerobe Broth ( $F A B$, Laboratory M, Bury, UK). A 50- $\mu \mathrm{L}$ sample of each serial dilution as well as of the undiluted sample were plated onto fastidious anaerobe agar (FAA, Laboratory M) with 5\% defibrinated sheep blood and containing $1 \mathrm{~mL} / \mathrm{L}$ of haemin and $1 \mathrm{~mL} / \mathrm{L}$ of vitamin $\mathrm{K} 1$. Bacterial plates were incubated at $37^{\circ} \mathrm{C}$ under anaerobic conditions $\left(10 \% \mathrm{CO}_{2}, 10 \% \mathrm{H}_{2}\right.$ and $\left.80 \% \mathrm{~N}_{2}\right)$ for up to 14 days. Samples were also plated onto brain heart infusion (BHI) agar with 5\% sheep blood (Oxoid, Basingstoke, UK) to allow growth of aerobic and facultative anaerobic microorganisms. The BHI plates were aerobically incubated at $37^{\circ} \mathrm{C}$ for 2 days. 
A total of 220 strains was isolated by culture and initially characterized according to their gaseous requirements, Gram-stain characteristic and ability to produce catalase. They were then stored at $-80{ }^{\circ} \mathrm{C}$ for further molecular identification.

\section{$16 S$ rRNA Sequencing}

The DNA of each previously isolated bacterium (220 strains) was extracted by using OIAamp DNA Minikit (Qiagen, Valencia, CA, USA) according to the manufacturer's instructions. After extraction, the universal amplification by polymerase chain reaction (PCR) was performed in a total volume of $50 \mathrm{uL}$ containing: $5 \mu \mathrm{L}$ of template DNA, $5 \mu \mathrm{L}$ of 10X PCR buffer, $1.5 \mu \mathrm{L}$ of $25 \mathrm{mmol} / \mathrm{L}$ $\mathrm{MgCl}_{2}, 4.0 \mu \mathrm{L}$ of DNTP solutions (25 mmol/L each), 1 $\mu \mathrm{L}$ of 25 pmol forward and universal primer (D88 - 5' GAGAGTTGATYMTGGCTCAG $3^{\prime}$ ) and reverse universal primer (E94 - 5' GAAGGAGGTGWTCCARCCGCA 3'), $0.5 \mu \mathrm{L}$ of $5 \mathrm{U} / \mathrm{mL}$ Platinum Taq Polymerase and $32 \mu \mathrm{L}$ of sterile distilled water (14).

The reagents were synthesized and provided by Invitrogen (Carlsbad, CA, USA). Genomic DNA of $P$. gingivalis (ATCC 33277) and sterile distilled water were used as positive and negative controls, respectively. The reaction was performed in a DNA thermocycler (GenePro, Bioer-Technology, Hangzhou, China) adjusted to initial denaturation step at $94^{\circ} \mathrm{C}$ for 4 min followed by 30 cycles at $94^{\circ} \mathrm{C}$ for $45 \mathrm{~s}$ (denaturation), $60^{\circ} \mathrm{C}$ for $45 \mathrm{~s}$ (annealing), $72{ }^{\circ} \mathrm{C}$ for $90 \mathrm{~s}$ (extension), and a final extension step at $72{ }^{\circ} \mathrm{C}$ for $15 \mathrm{~min}$.

Two independent PCRs were performed for each sample and the PCR products were submitted to electrophoresis in $1 \%$ agarose gel stained with $0.5 \mu \mathrm{L} / \mathrm{mL}$ ethidium bromide using $1 \mathrm{~kb}$ DNA ladder as molecular size marker. Positive reactions were determined by the presence of bands of appropriate size ( 1500 base pair) and then the PCR products were purified by using OIAquick Gel Extraction (Qiagen, Hiden, Germany).

Purified PCR products were sequenced by using the ABI 3730 DNA Analyzer, with the BigDye Terminator Cycle Sequencing Kit (Applied Biosystems, California, EUA) using primer 533R (5' TKACCGCGGCTGCTG 3'). Sequences of approximately 600 bases were obtained, inspected and edited using the software BioEdit (www.mbio.ncsu. edu/BioEdit/bioedit.html), and the identity/approximate phylogenetic position was obtained by comparison with $16 \mathrm{~S}$ rRNA gene sequences of the GenBank database from National Center of Biotechnology Information (www.ncbi. nImnih.gov) through the basic local alignment search tool (BLAST). Sequences with more than 4 ambiguous characters or shorter than 500 bases were discarded, and it was considered at least 98\% similarity level (15).

\section{Clonal Analysis}

Sequencing did not identify 5 of 220 strains isolated by culture because the sequences obtained were inadequate. They had many ambiguous characters or a sequence length too short for comparison with those in the GenBank. Therefore, further clonal analysis and sequencing of the strains was performed in order to get the microbial identification.

After DNA extraction from these samples, the universal amplification of $16 \mathrm{~S}$ rRNA gene and purification was performed following the protocol described above. The purified 165 rRNA gene products were ligated into the pCR2.1-TOPO vector (TOPO TA Cloning Kit - Invitrogen, Carlsbad, CA, USA) and inserted into electrocompetent $\mathrm{DH} 5 \alpha$ Escherichia coli by means of electroporation (MicroPulser, Bio-Rad Laboratories, Hercules, CA, USA). The transformed cells were plated onto Luria-Bertani agar plates supplemented with ampicillin $(100 \mathrm{mg} / \mathrm{mL})$ and $\mathrm{X}$-Gal (Promega), and then incubated overnight. Ninetysix white colonies per sample were randomly selected, suspended in $40 \mu \mathrm{L}$ of $10 \mathrm{mmol} / \mathrm{L}$ Tris-EDTA, and used as template $(5 \mu \mathrm{L})$ to determine the correct sizes of the inserts by PCR. Amplification reaction was performed with M13 forward (5' GTAAAACGACGGCCAG 3') and M13 reverse (5' CAGGAAACAGCTATGAC $3^{\prime}$ ) primers. The cycling conditions comprised an initial denaturation at $94^{\circ} \mathrm{C}$ for $10 \mathrm{~min}$ and included 30 cycles at $94{ }^{\circ} \mathrm{C}$ for $45 \mathrm{~s}$ (denaturation), 60 ${ }^{\circ} \mathrm{C}$ for $45 \mathrm{~s}$ (annealing), and $72{ }^{\circ} \mathrm{C}$ for $90 \mathrm{~s}$ (extension), followed by a final extension at $72{ }^{\circ} \mathrm{C}$ for $10 \mathrm{~min}$. The PCR products (approximately 1,500 bp) were submitted to electrophoresis in 1\% agarose gel and purified with GTX PCR DNA Purification kit (GE Healthcare, Buckinghamshire, UK) before sequencing, which was performed following the protocol described above.

\section{Statistical Analysis}

The data collected for each case were typed onto a spreadsheet and statistically analysed using SPSS for Windows (SPSS Inc, Chicago, IL, USA). The Pearson chisquare or the one-sided Fisher's Exact test, as appropriate, was chosen to test the null hypothesis that there was no relationship between microbial findings and clinical features and between any pair of bacterial species recovered from the root canal. The odds ratio was employed to classify the associations between bacterial species as positive or negative. Positive associations were those with an average odds ratio $(\mathrm{OR})>2.0$ and negative with an average odds of a ratio $<0.5$. A 95\% confidence interval $(\mathrm{Cl})$ was established. The significant level was set at $5 \%$.

\section{Results}

All 20 patients presented with spontaneous pain and 
pain to percussion. Twelve teeth were single-rooted and 8 multi-rooted. Eight teeth were restored, 8 presented with caries and 4 were sound teeth.

From a total of 220 strains isolated by culture, 215 were identified by $16 \mathrm{~S}$ rRNA sequencing. Five strains that were not identified by sequencing were submitted to the clonal analysis and 3 out of 5 cloned strains were identified.

Molecular methods allowed the identification of $99 \%$ of the isolates. Fiftynine different bacteria were identified. Strict anaerobes were found including 27 anaerobic Gram-negative bacteria (24 rods, 3 cocci), 23 anaerobic Gram-positive bacteria (19 rods, 4 cocci); 8 facultative Gram-positive bacteria (3 rods, 5 cocci) and 1 facultative Gram-negative bacterium (1 rod). The most frequently identified bacteria were Prevotella buccae (10/20), Pseudoramibacter alactolyticus (9/20), Prevotella nigrescens (8/20), Parvimonas micra (7/20), Dialister invisus (6/20), Filifactor alocis (4/20), Prevotella tannerae (4/20), Peptostreptococcus stomatis (4/20), Fusobacterium spp. (3/20) (Table 1). The number of bacterial species found in root canals varied from 2 to 12 (average 6).

Six phyla were detected including Firmicutes, Bacteroidetes, Actinobacteria, Proteobacteria, Fusobacteria and Synergistetes (Fig. 1).

Regarding the 5 cloned strains, two could still not be identified. The following microorganisms were found after cloning the 3 strains: Pseudoramibacteralactolyticusand Bacillus licheniformis (1/3); Pyramidobacter piscolens, Campylobacter rectus, Phocaeicola abscessus and Parvimonas micra (2/3) and Veillonella sp (3/3).

No association was found between microbial findings and clinical features. Positive association was found between Prevotella buccae and Pseudoramibacter alactolyticus $(\mathrm{p}<0.05 ; \mathrm{OR}=9.333 ; \mathrm{IC}=1.193$ 72.999), and between Parvimonas micra and Prevotella nigrescens $(\mathrm{p}<0.05 ; \mathrm{OR}=18.333$; $\mathrm{IC}=1.508-222.875$ ).

\section{Discussion}

Two hundred and twenty strains, including a wide range of anaerobic species, were previously isolated on culture plates from 20 root canals. It is possible that some extremely oxygen-sensitive species might still have not been identified. Basic microbiological methods were adapted to recover as many anaerobic species

Table 1. Bacteria, Gram-staining morphology, gaseous requirement, phyla, number and percentage of cases harboring the species

\begin{tabular}{|c|c|c|c|}
\hline Bacteria & $\begin{array}{c}\text { Gram-staining } \\
\text { morphology } \\
\text { and } \\
\text { Gaseous } \\
\text { requirement }\end{array}$ & Phyla & $\begin{array}{c}\text { Number } \\
\text { of case / } \\
\text { percentage }\end{array}$ \\
\hline Prevotella buccae & $-\operatorname{Rod} A N$ & Bacteroidetes & $10 / 50 \%$ \\
\hline $\begin{array}{l}\text { Pseudoramibacter } \\
\text { alactolyticus }\end{array}$ & $+\operatorname{Rod} \mathrm{AN}$ & Firmicutes & $9 / 45 \%$ \\
\hline Prevotella nigrescens & - Rod AN & Bacteroidetes & $8 / 40 \%$ \\
\hline Parvimonas micra & + Cocci AN & Firmicutes & $7 / 35 \%$ \\
\hline Dialister invisus & - Rod AN & Firmicutes & $6 / 30 \%$ \\
\hline Filifactor alocis & + Rod AN & Firmicutes & $4 / 20 \%$ \\
\hline $\begin{array}{l}\text { Peptostreptococcus } \\
\text { stomatis }\end{array}$ & + Cocci AN & Firmicutes & $4 / 20 \%$ \\
\hline Prevotella tannerae & - Rod AN & Bacteroidetes & $4 / 20 \%$ \\
\hline Propionibacterium acnes & $+\operatorname{Rod} \mathrm{AN}$ & Actinobacteria & $4 / 20 \%$ \\
\hline Slackia exigua & $+\operatorname{Rod} \mathrm{AN}$ & Actinobacteria & $4 / 20 \%$ \\
\hline Campylobacter rectus & $-\operatorname{Rod}$ AN & Proteobacteria & $3 / 15 \%$ \\
\hline Dialister pneumosintes & - Rod AN & Firmicutes & $3 / 15 \%$ \\
\hline Olsenella uli & $+\operatorname{Rod} \mathrm{AN}$ & Actinobacteria & $3 / 15 \%$ \\
\hline Phocaeicola abscessus & $-\operatorname{Rod}$ AN & Bacteroidetes & $3 / 15 \%$ \\
\hline Prevotella sp. & - Rod AN & Bacteroidetes & $3 / 15 \%$ \\
\hline Solobacterium moorei & $+\operatorname{Rod} \mathrm{AN}$ & Firmicutes & $3 / 15 \%$ \\
\hline $\begin{array}{l}\text { Pyramidobacter } \\
\text { piscolens }\end{array}$ & - Rod AN & Synergistetes & $3 / 10 \%$ \\
\hline Atopobium rimae & $+\operatorname{Rod} \mathrm{AN}$ & Actinobacteria & $2 / 10 \%$ \\
\hline Campylobacter gracilis & - Rod AN & Proteobacteria & $2 / 10 \%$ \\
\hline Eubacterium sp. & $+\operatorname{Rod} \mathrm{AN}$ & Firmicutes & $2 / 10 \%$ \\
\hline $\begin{array}{l}\text { Fusobacterium } \\
\text { nucleatum }\end{array}$ & - Rod AN & Fusobacteria & $2 / 10 \%$ \\
\hline Lactobacillus casei & $+\operatorname{Rod} F$ & Firmicutes & $2 / 10 \%$ \\
\hline Olsenella sp. & $+\operatorname{Rod}$ AN & Actinobacteria & $2 / 10 \%$ \\
\hline $\begin{array}{l}\text { Porphyromonas } \\
\text { gingivalis }\end{array}$ & - Rod AN & Bacteroidetes & $2 / 10 \%$ \\
\hline Prevotella baroniae & - Rod AN & Bacteroidetes & $2 / 10 \%$ \\
\hline Prevotella oralis & - Rod AN & Bacteroidetes & $2 / 10 \%$ \\
\hline Prevotella oris & - Rod AN & Bacteroidetes & $2 / 10 \%$ \\
\hline Streptococcus mutans & + Cocci F & Firmicutes & $2 / 10 \%$ \\
\hline Actinomyces georgiae & $+\operatorname{Rod} \mathrm{AN}$ & Actinobacteria & $1 / 5 \%$ \\
\hline
\end{tabular}


as possible. These measures involved immediate inoculation of samples into an appropriate transport medium, which was promptly incubated under suitable gaseous conditions, and prolonged incubation was used to avoid overlooking slow-growing organisms. Nevertheless, it was not expected that the media employed could be suitable for growth

of all microorganisms. For example, it was predictable that spirochaetes, shown to be

Table 1. Bacteria, Gram-staining morphology, gaseous requirement, phyla, number and percentage of cases harboring the species (continuation)

\begin{tabular}{|c|c|c|c|}
\hline $\begin{array}{l}\text { Aggregatibacter } \\
\text { aphrophilus }\end{array}$ & - Rod F & Proteobacteria & $1 / 5 \%$ \\
\hline Atopobium parvulum & $+\operatorname{Rod} \mathrm{AN}$ & Actinobacteria & $1 / 5 \%$ \\
\hline Bacillus drentensis & $+\operatorname{Rod} F$ & Firmicutes & $1 / 5 \%$ \\
\hline Bacillus licheniformis & $+\operatorname{Rod} F$ & Firmicutes & $1 / 5 \%$ \\
\hline Bifidobacterium dentium & $+\operatorname{Rod} \mathrm{AN}$ & Actinobacteria & $1 / 5 \%$ \\
\hline Bilophila wadsworthia & $-\operatorname{Rod} A N$ & Proteobacteria & $1 / 5 \%$ \\
\hline Enterococcus faecalis & + Cocci F & Firmicutes & $1 / 5 \%$ \\
\hline Eubacterium infirmum & $+\operatorname{Rod} \mathrm{AN}$ & Firmicutes & $1 / 5 \%$ \\
\hline $\begin{array}{l}\text { Fusobacterium } \\
\text { necrophorum }\end{array}$ & - Rod AN & Fusobacteria & $1 / 5 \%$ \\
\hline $\begin{array}{l}\text { Lactobacillus } \\
\text { catenaformis }\end{array}$ & $+\operatorname{Rod} \mathrm{AN}$ & Firmicutes & $1 / 5 \%$ \\
\hline Lactobacillus fermentum & $+\operatorname{Rod} \mathrm{AN}$ & Firmicutes & $1 / 5 \%$ \\
\hline Olsenella profusa & $+\operatorname{Rod} \mathrm{AN}$ & Actinobacteria & $1 / 5 \%$ \\
\hline $\begin{array}{l}\text { Parascardovia } \\
\text { denticolens }\end{array}$ & $+\operatorname{Rod}$ AN & Actinobacteria & $1 / 5 \%$ \\
\hline Parvimonas sp. & + Cocci AN & Firmicutes & $1 / 5 \%$ \\
\hline Peptococcus niger & + Cocci AN & Firmicutes & $1 / 5 \%$ \\
\hline Porphyromonas uenonis & - Rod AN & Bacteroidetes & $1 / 5 \%$ \\
\hline Prevotella denticola & - Rod AN & Bactedoidetes & $1 / 5 \%$ \\
\hline Prevotella marshii & $-\operatorname{Rod} A N$ & Bacteroidetes & $1 / 5 \%$ \\
\hline $\begin{array}{l}\text { Prevotella } \\
\text { melaninogenica }\end{array}$ & - Rod AN & Bactedoidetes & $1 / 5 \%$ \\
\hline $\begin{array}{l}\text { Prevotella } \\
\text { multisacharivorax }\end{array}$ & - Rod AN & Bacteroidetes & $1 / 5 \%$ \\
\hline Prevotella oulorum & - Rod AN & Bacteroidetes & $1 / 5 \%$ \\
\hline $\begin{array}{l}\text { Propionibacterium } \\
\text { acidifaciens }\end{array}$ & $+\operatorname{Rod} \mathrm{AN}$ & Actinobacteria & $1 / 5 \%$ \\
\hline Scardovia inopinata & $+\operatorname{Rod} \mathrm{AN}$ & Actinobacteria & $1 / 5 \%$ \\
\hline Selenomonas sp. & - Rod AN & Firmicutes & $1 / 5 \%$ \\
\hline $\begin{array}{l}\text { Staphylococcus } \\
\text { epidermidis }\end{array}$ & + Cocci F & Firmicutes & $1 / 5 \%$ \\
\hline Streptococcus anginosus & + Cocci F & Firmicutes & $1 / 5 \%$ \\
\hline Streptococcus gordonii & + Cocci F & Firmicutes & $1 / 5 \%$ \\
\hline Veillonella dispar & - Cocci AN & Firmicutes & $1 / 5 \%$ \\
\hline Veilonella parvula & - Cocci AN & Firmicutes & $1 / 5 \%$ \\
\hline Veilonella sp. & - Cocci AN & Firmicutes & $1 / 5 \%$ \\
\hline
\end{tabular}

+ = Gram-positive, - = Gram-negative; $\mathrm{AN}$ = strict anaerobe; $\mathrm{F}$ = facultative anaerobe. present in other studies using only molecular techniques $(8,16)$, would not survive on the media plate used here and consequently not isolated.

To date, there is no a single method capable of recovering every microorganism found in the pulp space and related structures (4). To overcome the limitations of culture and biochemical identification methods, technological advances have allowed the introduction of molecular methods for bacterial identification, leading to a better understanding of endodontic infection profile $(10,14,17-19)$.

The greatest advantage of open-ended molecular approaches for 16S rRNA analysis, such as cloning and sequencing of PCR products from polymicrobial infections, is the possibility of predicting the general microbiota involving fastidious and strain atypical phenotypic behavior, without searching for target species only $(11,12)$. Usually, the initial 500-bp sequence of 16S rRNA gene provides adequate differentiation and is sufficient for identification of clinical isolates $(20,21)$.

The method employed in this study enabled the isolation of 220 strains and identification of $99 \%$ of isolates, including 59 different species identified. Similar results were found by Drancourt et al. (22) and Song et al. (23), who identified $90 \%$ and $86 \%$, respectively, using $16 \mathrm{~S}$ rRNA sequencing.

Six out of 7 bacterial phyla detected only in dental abscess by molecular methods, were found in the root canals investigated. Our results showed that the majority of the bacteria isolated belonged to the phylum Firmicutes, which comprises the following species: Dialister invisus, Dialister pneumosintes, Filifactor alocis, Parvimonas micra, Peptostreptococcus stomatis, Pseudoramibacter alactolyticus, among others. The second most predominant phylum was Bacteroidetes, which comprises Porphyromonas gingivalis, Prevotella buccae, Prevotella nigrescens, Prevotella tannerae, 
among others. The higher prevalence of the phyla Firmicutes and Bacteroidetes in the root canals of teeth with AAA are in agreement with Siqueira and Roças (1).

The phylum Spirochaetes was not isolated from the root canals investigated and therefore, it was not sequenced. Due to the fastidious requirements of certain microorganisms such as spirochaetes and mycoplasma, the decision was made, in most studies, including ours, not to undertake isolation of every organism found. Paster et al. (14) found that $75 \%$ of oral species of Treponema, which belongs to the Spirochaetes phylum, have not been cultivated. They reported that the best model for exploring microbial diversity is based on isolating DNA from the target environment, PCR amplifying the ribosomal DNA (rDNA), cloning the amplicons into Escherichia coliand sequencing the cloned 16S rDNA inserts. Recently, the development of next-generation sequencing (NGS) technologies has permitted in-depth sequencing and data analyses to a deeper level than possible with standard molecular biological techniques (24). As a result, an in-depth study of endodontic microbial diversity can be carried out with amplified bacterial 16S rDNA sequences without cloning bias (25).

The microbiota of root canal associated with AAA was more diverse than the ones found in previous studies based only on conventional identification methods $(3,6,7)$, being predominated by anaerobic Gram-negative bacteria. Species including Dialister invisus, Filifactor alocis, Peptostreptococcus stomatis, Prevotella nigrescens and Prevotella tannerae were not reported in those studies.

The average of 6 bacteria per root canal supports the polymicrobial feature of the primary endodontic infection. Moreover, some species were recovered in only 1 or 2 patients, thus corroborating the idea of heterogeneous

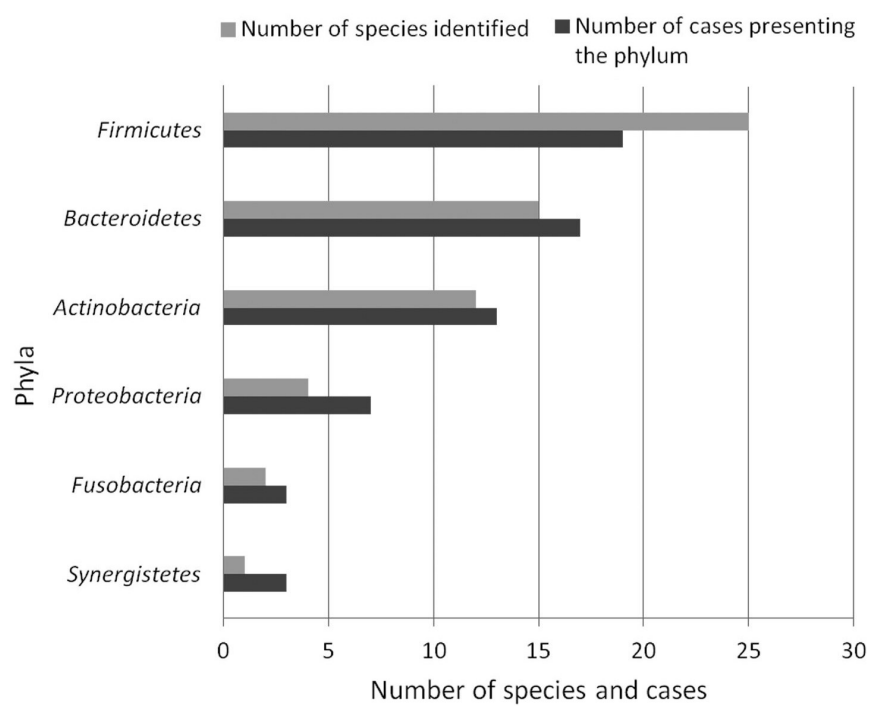

Figure 1. Phyla and number of species/cases. bacterial communities between the subjects $(2,8)$.

Gram-negative species correlated with signs and symptoms of AAA were also frequently identified in this study, as follows: Prevotella spp., Fusobacterium spp., Porphyromonas gingivalis, Dialister invisus, Dialister pneumosintes and Filifactor alocis. The presence of Gramnegatives has clinical significance due to the presence of the endotoxin (lipopolysaccharide; LPS), which is a cell envelope constituent and can be secreted from cell vesicles. LPS has many biological activities, including fever induction, cytotoxicity, fibrinolysis and can stimulate production of bradykinin, a potent pain mediator. Clinical investigations have elucidated the strong correlation between higher levels of endotoxin in root canals with spontaneous pain and clinical symptomatology, such as pain on palpation, tenderness to percussion and exudation (26).

It was also detected a great number of Gram-positive bacteria, such as Parvimonas micra, Peptostreptococcus stomatis, Pseudoramibacteralactolyticusand Slackia exigua, whose cell walls contain peptidoglycans and lipoteichoic acid. They are capable of influencing inflammatory reactions and enhance the pathogenicity of anaerobic Gram-negatives, mainly the black-pigmented ones $(13,27)$.

Inthepresentwork Parvimonasmicra and Pseudoramibacter alactolyticus (both Gram-positive) were frequently isolated in association with Prevotella nigrescens and Prevotella buccae (both Gram-negative), respectively, contributing to the pain presented by the patients. Furthermore, they are strict anaerobes and susceptible to conventional endodontic strategies, which include mechanical debridement, chemical irrigation or other antimicrobial protocols and intra-canal medicaments $(24,28)$.

It is known that endodontic therapy changes the environment inside the root canal in different ways. The main effect may be the change in the anaerobiosis. The treatment may also disturb established nutritional interrelationships among the bacteria, eliminating some bacteria that might be essential to the growth of others, or leaving some bacteria whose presence will prevent the growth of others (28).

The control or elimination of microorganisms and possible substrate must be the goal in every endodontic case. Considering the microbiological etiology of the disease, it is important to know as much as possible the endodontic microbiota, in order to understand the differences in the manifestation of the clinical features, improve the prognosis and lead to the development of rational treatment strategies $(1,12)$.

The cultivable bacteria present in the root canals of teeth associated with AAA, using the 16S rRNA gene sequencing technique complemented by clonal analysis, was more diverse than the ones found in 
previous studies based only on conventional identification methods.

It was concluded that the microbiota of Infected root canal associated with acute apical abscess is diverse and heterogeneous, composed mainly of anaerobic Gramnegative bacteria, with the great majority belonging to the phyla Firmicutes and Bacteroidetes.

\section{Resumo}

0 objetivo deste estudo foi investigar a composição bacteriana de canais radiculares associados com abscesso apical agudo através de identificação molecular (16S rRNA) de bactérias cultiváveis. Duzentas e vinte cepas, de 20 casos, isoladas por cultura foram submetidas a extração de DNA e amplificação do gene $16 \mathrm{~S}$ rRNA (PCR), seguido de sequenciamento. As sequências de nucleotideos obtidas foram comparadas com o banco de dados (GenBank) do National Center of Biotechnology Information através do BLAST. Cepas não identificadas pelo sequenciamento foram submetidas à clonagem. Associação de achados microbiológicos e características clínicas e associação entre espécies bacterianas também foram investigadas. Cinquenta e nove bactérias cultiváveis diferentes foram identificadas pelo sequenciamento do gene $16 \mathrm{~S}$ rRNA, pertencentes a 6 filos, numa média de 6 espécies por canal. Método molecular permitiu identificação de $99 \%$ das cepas isoladas. As bactérias mais frequentes foram Prevotella spp., Pseudoramibacter alactolyticus, Parvimonas micra, Dialister invisus, Filifactor alocis, Peptostreptococcus stomatis. Associação positiva foi encontrada entre Prevotella buccae e Pseudoramibacter alactolyticus, e entre Parvimonas micra e Prevotella nigrescens $(\mathrm{p}<0,05)$. Foi concluido que a microbiota de canais radiculares infectados associados com abscesso apical agudo é diversa e heterogênea, composta principalmente por anaeróbios Gram-negativos, pertencentes aos filos Firmicutes e Bacteroidetes.

\section{Acknowledgements}

This study was supported by the Brazilian Agencies FAPESP (Grants 2009/07760-5 and 2011/09047-4), CNPQ (Grants 302575/2009 and 308162/2014-5) and CAPES. We would like to thank Pâmela Pontes and Tiago Pereira da Rosa for their technical assistance.

\section{References}

1. Siqueira JF Jr, Rôças IN. Microbiology and treatment of acute apical abscesses. Clin Microbiol Rev 2013;26:255-273.

2. Montagner $F$, Gomes BP, Kumar PS. Molecular fingerprinting reveals the presence of unique communities associated with paired samples of root canals and acute apical abscesses. J Endod 2012;36:1475-1479.

3. Munson MA, Pitt-Ford T, Chong B, Weightman A, Wade WG. Molecular and cultural analysis of the microflora associated with endodontic infections. J Dent Res 2002;81:761-766.

4. Ozok AR, Persoon IF, Huse SM, Keijser BJF, Wesselink PR, Crielaard W, et al.. Ecology of the microbiome of the infected root canal system: a comparison between apical and coronal root segments. Int Endod J 2012;45:530-541.

5. Sundqvist G, Johansson E, Sjögren U. Prevalence of black-pigmented Bacteroides species in root canal infections. J Endod 1989;15:13-19.

6. Sousa EL, Ferraz CC, Gomes BP, Pinheiro ET, Teixeira FB, de Souza-Filho FJ. Bacteriological study of root canals associated with periapical abscesses. Oral Surg Oral Med Oral Pathol Oral Radiol Endod 2003;96:332-339.

7. Sousa EL, Gomes BP, Jacinto RC, Zaia AA, Ferraz CC. Microbiological profile and antimicrobial susceptibility pattern of infected root canals associated with periapical abscesses. Eur J Clin Microbiol Infect Dis 2013;32:573-580.

8. Montagner F, Jacinto RC, Signoretti FG, Gomes BP. Treponema species detected in infected root canals and acute apical abscess exudates. Endod 2010;36;1796-1799.

9. Murad CF, Sassone LM, Faveri M, Hirata R Jr, Figueiredo L, Feres M. Microbial diversity in persistent root canal infections investigated by checkerboard DNA-DNA hybridization. J Endod 2014;40:899-906.

10. Siqueira JF, Rocas IN. Exploiting molecular methods to explore endodontic infections: Part 1-current molecular technologies for microbiological diagnosis. J Endod 2005;31:411-423.

11. Siqueira JF, Roças IN, Paiva SSM, Magalhães-Pinto T. Cultivable bacteria in infected root canal as identified by $16 \mathrm{~S}$ rRNA gene sequencing. Oral Microbiol and Immunol 2007;22:266-271.

12. Tzanetakis GN, Azcarate-Peril MA, Zachaki $S$, Panopoulos $P$, Kontakiotis EG, Madianos PN, et al.. Comparison of bacterial community composition of primary and persistent endodontic infections using pyrosequencing. J Endod 2015;41:1226-1233.

13. Gomes BP, Pinheiro ET, Gade-Neto CR, Sousa EL, Ferraz CC, Zaia AA, et al.. Microbiological examination of infected dental root canals. Oral Microbiol Immunol 2004;19:71-76.

14. Paster BJ, Boches SK, Galvin JL, Ericson RE, Lau CN, Levanos VA, et al.. Bacterial diversity in human subgingival plaque. J Bacteriol 2001;:183:3770-3783.

15. Ribeiro AC, Matarazzo F, Faveri M, Zezell DM, Mayer MPA. Exploring bacterial diversity of endodontic microbiota by cloning and sequencing 16S rRNA. J Endod 2011;37:922-926.

16. Jung IY, Choi BK, Kum KY, Yoo YJ, Yoon TC, Lee SJ. Identification of oral spirochetes at the species level and their association with other bacteria in endodontic infections. Oral Surg Oral Med Oral Pathol Oral Radiol Endod 2001;92:329-334.

17. Sakamoto M, Rocas IN, Siqueira JF, Benno Y. Molecular analysis of bacteria in asymptomatic and symptomatic endodontic infections. Oral Microbiol Immunol 2006;21:112-122.

18. Sassone $L M$, Fidel $R$, Faveri $M$, Fidel $S$, Figueiredo $L$, Feres $M$. Microbiological evaluation of primary endodontic infections in teeth with and without sinus tract. Int Endod J 2008;41:508-515.

19. Sassone LM, Fidel RA, Faveri M, Guerra F, Figueiredo L, Fidel SR, et al.. A microbiological profile of symptomatic teeth with primary endodontic infection. J Endod 2009;34:541-545.

20. Claridge JE 3rd. Impact of $16 \mathrm{~S}$ rRNA gene sequence analysis for identification of bacterial on clinical microbiology and infectious diseases. Clin Microbiol Rev 2004;17:840-862.

21. Turnbaugh PJ, Ley RE, Hamady M, Fraser-Liggett CM, Knight R, Gordon JI. The Human Mocrobiome Project. Nature 2007;449:804-810.

22. Drancourt M, Bollet C, Carlioz A, Martelin R, Gayral JP, Raoult D. 16S ribosomal DNA sequence analysis of a large collection of environmental and clinical unidentifiable bacterial isolates. J Clin Microbiol 2000;38:3623-3630.

23. Song $Y$, Lui $C$, McTeague $M$, Finegold SM. 16 ribossomal sequence-based analysis of clinically significant gram-positive cocci. J Clin Microbiol 2003:41:1363-1369.

24. Gomes BP, Berber VB, Kokaras AS, Chen T, Paster BJ. Microbiomes of endodontic-periodontal lesions before and after chemomechanical preparation. J Endod 2015;41:1975-1984.

25. Li L, Hsiao WW, Nandakumar R, Barbuto SM, Mongodin EF, Paster BJ, Fraser-Liggett CM, Fouad AF. Analyzing endodontic infections by deep coverage pyrosequencing. J Dent Res 2010;89:980-984.

26. Martinho FC, Chiesa WMM, Leite FRM, Cirelli JA, Gomes BPFA Antigenicity of primary endodontic infection against macrophages by the levels of PGE2 production. J Endod 2001;37:602-607.

27. Jacinto RC, Gomes BP, Ferraz CCR, Zaia AA, Souza-Filho FJ. Microbiological analysis of infected root canals from symptomatic and asymptomatic teeth with periapical periodontitis and the antimicrobial susceptibility of some isolated anaerobic bacteria. Oral Microbiol Immunol 2003;18:285-292.

28. Gomes BP, Lilley JD, Drucker DB. Variations in the susceptibilities of components of the endodontic microflora to biomechanical procedures. Int Endod J. 1996; 29:235-241 